\title{
INTERNATIONAL Overseas doctors of the NHS: migration, transition, challenges and towards resolution
}

\author{
Authors: Mustafa Jalal, ${ }^{A}$ Karna Dev Bardhan, ${ }^{B}$ David Sanders ${ }^{C}$ and Jan Illing ${ }^{D}$
}

Overseas doctors are playing an important role in the successful running of the NHS. They represent one-third of the total number of UK doctors and include doctors from the European Economic Area and international medical graduates. The main aim of this review is to explore the challenges that overseas doctors might face when they take up their first job in the UK. We conducted literature search using MEDLINE and EMBASE databases. The inclusion and exclusion criteria were designed to include published literature concerning overseas doctors in the UK and the NHS. Lack of information about the UK health system; language and communication challenges; clinical, educational and work-culture challenges; and discrimination challenges are some of the difficulties that overseas doctors might experience. Understanding these challenges and providing support are important steps in helping overseas doctors to make a smooth transition.

KEYWORDS: Overseas doctors, NHS, IMG, communication challenges, induction programmes

\section{Background}

Since its inception in 1948, the NHS has relied heavily on the contribution of overseas doctors in the successful running of its services. The number of medical schools in the UK has increased but medicine, its science and practice, has also expanded. ${ }^{1}$ Therefore, the NHS will continue to depend on doctors from overseas to fill the gap. ${ }^{2}$ Overseas doctors face challenges entering a new culture, as does the service itself when taking on those who are unfamiliar with medical traditions in Britain. This continuing complex interaction has become more urgent in the face of Brexit.

The purpose of this contribution is to review some of the principal challenges overseas doctors face. All statements are based on the literature, except those which express our personal views.

Authors: A specialist registrar in gastroenterology, Royal Hallamshire Hospital, Sheffield, UK; ${ }^{B}$ emeritus consultant gastroenterologist, Rotherham Hospital, Rotherham, UK; C professor of gastroenterology, Royal Hallamshire Hospital, Sheffield, UK;

D professor of medical education research, Newcastle University, Newcastle upon Tyne, UK

\section{Introduction}

The term 'overseas doctors' is applied to those who have graduated outside the UK, and embraces two groups: international medical graduates (IMG) and European Economic Area (EEA) graduates. ${ }^{3}$ In 1957 , overseas doctors represented about $12 \%$ of the total medical workforce, the majority having migrated from Europe during or after World War II. ${ }^{4}$ The proportion has increased gradually. Recent data indicate non-UK graduates comprise $37 \%$ of the total number of doctors: $26 \%$ are IMGs and $11 \%$ from EEA. ${ }^{5}$ IMGs are required to first pass a set of examinations which will then entitle them to practice in the UK. These comprise the Professional and Linguistic Assessment Board test (PLAB) and the International English Language Test System. EEA and Swiss nationals, however, are exempt from PLAB. ${ }^{6}$

Regulations controlling the entrance of overseas doctors have repeatedly changed. ${ }^{7}$ Vacant posts increased during 2001-2006, leading to a rapid influx of overseas doctors, causing some donor countries to struggle to maintain their services. ${ }^{8}$ The influx subsequently exceeded demand, causing many doctors to remain unemployed for long periods. ${ }^{9,10}$ The work permit visa, introduced in 2006, restricted the entry of IMGs, aiming to achieve a better balance between 'supply and demand'. The struggle to achieve a better supply, however, has continued and the UK decision to leave the European Union is likely to adversely affect recruiting and retaining European doctors. ${ }^{11}$ This major issue has been recognised by the UK government which recently announced its decision to remove the restriction on overseas doctors and nurses entering through the Tier 2 visa route. ${ }^{12}$

\section{Methodology}

A literature search was conducted using the Ovid search engine. MEDLINE and EMBASE were searched from 1946 and 1974, respectively. The search looked for the following words and synonyms: overseas doctor (foreign doctor, international medical graduate, IMG, European doctor, EU doctor) and United Kingdom (UK, Great Britain, GB) and NHS. The initial search revealed 323 papers. Table 1 shows the inclusion and exclusion criteria. Duplicate papers were removed at the initial review. Titles, abstract and full text were screened to identify relevant articles for full review. The bibliography was supplemented with relevant articles and reports known to the authors. The descriptive findings were pooled and grouped into challenges themes. The initial search was conducted in 2013. Since then, 22 papers and reports have been added to update the manuscript. 
Table 1. Inclusion and exclusion criteria

\begin{tabular}{ll}
$\begin{array}{l}\text { Inclusion criteria } \\
\text { Papers covered overseas, European } \\
\text { or IMG doctors }\end{array}$ & $\begin{array}{l}\text { Exclusion criteria } \\
\text { Papers covered overseas } \\
\text { doctors in other countries }\end{array}$ \\
$\begin{array}{l}\text { In the NHS or in the UK } \\
\text { In English }\end{array}$ & Not in English \\
\hline IMG = international medical graduates &
\end{tabular}

From inquiry to PLAB: The Merrison inquiry (1975)

Concerns on performance of some overseas doctors triggered this landmark inquiry. Its conclusion highlighted major issues, one being that the performance of a 'significant number' of overseas doctors fell below expectations. ${ }^{13}$ The following extract summarises the problem well:

It would be surprising if doctors from overseas did not lack knowledge of the operation of the NHS, did not find difficulty in understanding the significance of the euphemisms and colloquialisms which for many patients are their most accurate means of expression, and even more surprising if they could easily come to grips with the variety of dialects they may encounter. $^{14}$

This led to the introduction of a new method to assess clinical and language skills, the Temporary Registration Assessments Board, which finally developed into the PLAB test in $1978 .^{15}$

Overseas doctors gain their primary medical qualification from about 150 diverse countries, ${ }^{16}$ with inherent variability of medical regulations between country of origin and the UK. ${ }^{17}$ Coupled with this is the frequently inadequate information about the NHS and its structure, ${ }^{16,18,19}$ the reality often differs from expectations. ${ }^{20}$ There may be lack of information on individual posts, particularly for competitive specialties. ${ }^{21,22}$ A further issue for overseas doctors is that they may not be made aware of the new regulations requiring them to obtain medico-legal insurance during clinical practice in the UK, hence may miss this important support when most needed. ${ }^{23}$

\section{Language and knowledge of 'local euphemism and colloquialism'}

As the satisfactory practice of medicine requires knowledge of language and culture, overseas graduates require time to become familiar with practice in the UK, particularly when their training in medical school was not in English. Even when English is the medium of instruction, the language learnt may vary from its day-to-day use by reasons of grammar, phrases and idioms. ${ }^{24-26}$ The General Medical Council (GMC) report neatly summarises the issues as ranged from "difficulties with subtleties of language and dialect to misunderstandings of the nuances of non-verbal communication and social and behavioural norms.'16

Communication, a two-way process, is affected by the patient's understanding, which in turn is influenced by his/her social and educational background and local dialect - subtleties which the overseas doctor may not be in a position to fully understand. ${ }^{25,27,28}$

The corollary is that the patient, too, needs to be aware of a non-UK graduate's own limitations in this area. Shortcomings on either side lead to weaknesses in how a doctor takes a patient's history, explains management plans, and when handing over care to another doctor. ${ }^{26}$

Yet more complexities arise when non-verbal gestures matter, such as eye contact, facial expression or body language, which hold cultural clues which may be misinterpreted. ${ }^{21}$ A particular difficulty is when discussing sensitive issues such as a sexual history, and problems of a different sort when breaking bad news. ${ }^{28}$

\section{Clinical, educational and work-culture challenges}

Recognised training posts are ideal for they should provide continuing structured training and graded exposure to responsibilities. In reality, however, a disproportionate number of overseas doctors have to either wait for a long period to secure such a post or, in desperation, accept a non-training post. ${ }^{29-31}$ An example is the out-of-hours service. Such positions often provide care during unsociable hours, ${ }^{32}$ which local graduates avoid or are reluctant to fill because they lack working time restrictions or because the workload is excessive. ${ }^{33}$ The mismatch was accentuated when priority for higher specialty training posts was given to UK and EEA graduates. ${ }^{21}$ Further examples included lack of study leave and professional development opportunities. Worst of all, the time spent in such posts did not count towards specialist training when a post is finally secured. ${ }^{30}$ The overseas doctors may not be aware in advance of the 'negative' aspects of non-training posts.

Disease patterns may vary markedly between a doctor's country of origin and the UK, as might clinical practice, ${ }^{25,28,34}$ the medications available and how these are best used. ${ }^{25}$

Mental capacity, end-of-life decisions, confidentiality and consent are some of the many issues encountered, ${ }^{21,25,28,35,36}$ complex as they are interwoven with morality, culture, and perception. These are encountered by health professionals worldwide but their resolution varies from country to country, guided by local culture and law. In the UK, decisions are shaped by the ethical and professional frameworks set out by the GMC. ${ }^{21}$ In such grey areas it is understandable why overseas doctors have experienced difficulties, which sometimes have led to unsatisfactory outcomes. ${ }^{21,37,38}$ Sharing clinical information with a patient and family and taking consent may vary between countries and cultures, shaped by laws and need to be addressed early in a doctor's career. ${ }^{39}$

Working effectively within teams, now an almost universal practice, is more complex than it at first appears. Decisions are best made when all necessary information is available, which in turn is possible only when the consultant invites even the most junior members to contribute. Such subtleties may not be apparent to an overseas doctor if they have previously worked in a more rigid, hierarchical 'top-down' structure, where the most junior speaks 'only when spoken to', otherwise remains silent which, in the UK context, may be perceived as being a poor team player. ${ }^{28}$

Recognising and admitting a mistake, thereby learning from it, is now becoming much more conventional in the NHS. The professional duty of candour published by the GMC and Nursing and Midwifery Council advocates an open and transparent environment and encourages healthcare professionals to be honest when mistakes happen. ${ }^{40}$ Availability of similar guidance may vary across countries and therefore some overseas doctors may be unfamiliar with the actions they should take if mistakes occur. ${ }^{28}$ The consequence is missing a real opportunity to 'learn on the job'. Other important abilities like time management, 
prioritisation and IT skills may be inadequate or not freely available, compared to local graduates. ${ }^{28,41}$

Communication skills are tested for in postgraduate examinations, such as MRCP(UK), at which an overseas doctor may yet again be disadvantaged for all the reasons explained above. ${ }^{42}$

Finally, revalidation was introduced in the UK in 2012 by the GMC to ensure that all doctors continue to be up to date and fit to practice, ${ }^{43}$ a process employed in only a limited number of countries. $^{17,25}$

\section{Discrimination challenges}

\section{Bullying, harassment and bias}

Bullying was reported to be experienced equally by UK graduates and overseas doctors, the difference being the latter were less likely to take appropriate action, for example reporting the incident to the human resources department. ${ }^{44,45}$ Bullying led to increased stress, anxiety and depression, and decreased selfconfidence. For the hospital, such problems impact functioning as they lead to decreased productivity, increased absence from sickness and loss of staff. 44,45

Esmail and Everington (1992) carried out an unusual study. As a pilot, they developed curriculum vitae for 'six equivalent applicants - three with Asian names and three with English names. All applicants were male, of the same age, educated and trained in Britain, and with a similar length of experience in district general or teaching hospitals. All were at the same stage of their career, applying for their first senior house officer post in a non-teaching hospital. ${ }^{46}$ Based on the pilot, forty-six applications (23 English names, 23 Asian names) were created and sent to 23 different posts covering a range of specialties. Twelve of the 18 applications shortlisted had English names. The authors repeated their investigation using the same methods five years later and obtained similar findings with preference to English names. ${ }^{47}$

\section{Referral to GMC}

The National Clinical Assessment Service (NCAS) was launched in 2001 after recommendations made by the chief medical officer for England in $1999 . .^{48}$ One in 190 doctors had been referred to NCAS but only one in 17 led to formal assessment. ${ }^{49}$ In its analysis of case referrals 2001-2009, NCAS concluded that the likelihood of a non-UK graduate being referred for malpractice is higher than that of the UK counterpart and white practitioners qualified in the UK are at lower risk of exclusion.

In a separate investigation, Humphrey and colleagues ${ }^{19}$ examined the outcome of 7526 inquiries made to the GMC until April 2009: 62\% were doctors qualified in the UK, $8 \%$ in Europe, and 29\% were IMG. Most of the UK-qualified referrals were categorised as 'complaints', whilst the majority for overseas doctors were 'referrals', a stage higher (a term which in the authors' view seems counterintuitive for it gives no indication of severity). Overseas doctors were more likely to receive harsh decisions, for example suspension or erasure, when 'fitness to practice' was assessed. ${ }^{19}$

\section{Current methods of integration into the NHS}

The most common approaches were through clinical attachments and induction programmes. ${ }^{18,33,50,51}$ There is overlap between them but induction programmes have the advantage of structure, and other relevant courses such as communication skills. The history of clinical attachment goes back to 1966 and since then it has remained the main route of entry for overseas doctors to the NHS. Most hospitals now encourage this approach. ${ }^{51}$ The GMC has recently launched a half-day induction programme for doctors who are new to the country ('Welcome to UK practice'). The programme runs repeatedly through the year, is free of charge and covers topics that are important in day-to-day practice. Examples are good medical practice guidance and common ethical challenges, with an additional complementary online scenario tool. ${ }^{52}$ In addition, many hospitals and trusts have started to offer help for overseas doctors, noticeably for the last few years, ranging from completing computer-based modules to specific induction programmes.

\section{Towards resolution}

These suggestions stem from reviewing the literature and from working in the NHS. We recognise these ambitious suggestions will need to be modified in the light of experience, will need resources, time and patience to develop and implement. Nevertheless, these may prove to be important steps in the right direction.

\section{Making the necessary information available in advance}

A single website in plain language dedicated to overseas doctors would help to provide guidance in several areas. Examples include: GMC registration, medico-legal insurance, the degree of competition for training posts in each specialty and revalidation. Helpful notes on UK customs and culture would complete the picture.

\section{Bridging the culture gap}

Healthcare professionals and organisations need to understand the clinical and cultural differences, which in turn can enhance overseas doctors' performance and their retention. ${ }^{22}$ Supervisors and mentors, too, benefit from such knowledge allowing them to understand cultural differences and help overseas doctors fit within the NHS, with its own distinctive ethos. ${ }^{22}$ The deficit in expertise in the field of integrating overseas doctors and the financial burden on organisations will continue to lead to a shortfall in providing individualised and on-going support. ${ }^{22,53}$

The work of the social psychologist, Geert Hofstede, on cultural dimensions may help to understand variations across countries. The Hofstede theory states the culture of a country is supported mainly by four domains: power distance, uncertainty avoidance, individualism vs collectivism and masculinity vs femininity. ${ }^{54}$ Every national culture has its unique profile, according to strength or weakness of these domains.

Morrow et al $(2013)^{37}$ have 'fine-tuned' the domains to pick up subtle differences and have provided several examples how the intermix varies from country to country and its impact on their clinical practice (Table 2).

\section{A point of contact 'responsible officer'}

It is reassuring to meet a specified officer in each deanery, the 'point of contact person', who would offer guidance and help. Such 
Table 2. The Hofstede theory model with examples of its application in clinical practice in different cultures

$\begin{array}{ll}\begin{array}{l}\text { Hofstede theory } \\ \text { domain }\end{array} & \text { Explanation } \\ \text { Power distance } & \begin{array}{l}\text { In large organisations, which commonly } \\ \text { have hierarchical structures, authority and } \\ \text { power, actual or perceived, is almost by } \\ \text { definition distributed unequally, those at } \\ \text { the top having most. Such inequality is } \\ \text { accepted by the leaders and the led. }\end{array}\end{array}$

Uncertainty Members of a group commonly react, or avoidance

Individualism versus collectivism

Masculinity versus femininity

\section{Examples of countries}

High 'power distance' countries are France and India. Low 'power distance' countries are Austria and Israel.

Strong 'uncertainty avoidance' countries are Japan and Greece.

Weak 'uncertainty avoidance' countries are Denmark and Hong Kong.

'Individualistic' cultures are found in the USA and UK, while 'collectivism' is found in Peru and Iran.

\section{Example in clinical practice}

In a societal culture of high 'power distance', the patient perceives the doctor to be in a superior position; the doctor in turn accepts this, directs the consultation, which then becomes unidirectional. ${ }^{37}$

In a culture of low 'power distance', however, the patient and doctor regard themselves as equals, hence consultation becomes a bidirectional discussion. ${ }^{37}$

An example of 'uncertainty avoidance' is time made available per patient during clinics or ward rounds. In a strong 'uncertainty avoidance' culture, a rigid time management structure prevails, thus each patient is given precisely the same time and approached in the same manner. Doctors from countries with a high 'uncertainty avoidance' profile may find building a relation with a patient through empathy and non-verbal communication, such as eye contact, difficult. ${ }^{37}$

Doctors from countries with high 'collectivism' may appear to be less assertive, which may become obvious when working in a country like the UK. ${ }^{37}$

\section{own initiative.}

In 'collectivism', in contrast, individuals in the group prefer to be instructed on what they can and cannot do.

The emphasis in individualism is on being a good leader, while in 'collectivism' culture it is about being a good member.

This dimension reflects less the gender per se and more the culture associated with it. In 'masculine' countries assertiveness and competitiveness are acceptable, whereas in 'feminine' cultures the preferences are more on caring and improving the quality of life. The 'feminine' society treat male and female gender equally.
'Masculine' countries are Japan and USA.

'Feminine' countries are the Netherlands and the Nordic

countries.
Consultation and communication with patients and relatives is guided by societal perception of the role of men and women whether both are treated equally or differently.

Statements are referenced, except those which are the authors' personal views.

support should ideally be available before the doctor starts their first post and the contact maintained throughout the post.

\section{A national induction programme}

A mandatory national induction programme for overseas doctors complemented by existing local hospital inductions will help.

The curriculum could include sessions on 'culture', both that of the British way of life and, more specifically, of the NHS, as well as clinical skills.

The subtleties of the English language, subconscious in those who have grown up in the UK, may be unfamiliar to doctors from overseas. The induction programme would be a good forum to provide insights.

\section{Conclusion}

Overseas doctors continue to contribute significantly to the UK NHS but coming from a different culture and healthcare system creates certain challenges. The doctors need to understand the differences, whilse the host can help by making important information about the NHS and British culture readily accessible. Combined, these steps have the potential to lead to resolution, and smoothen the doctors' entry into the NHS.

\section{Acknowledgements}

We are grateful to Prof Sir John Temple for his valuable insights and suggestions. 
We are indebted to Beverley Mason, Karna Dev Bardhan's secretary. The work would not have got to this stage without her commitment to the project. She coordinated the meetings with Mustafa Jalal and Karna Dev Bardhan, and assisted with the editing of the manuscript. She is supported by The Bardhan Research \& Education Trust (Registered Charity No 328452): we are grateful to its trustees.

\section{References}

1 Bolton NRP. Medical school places in England from September 2018. Hous of Commons Librart 2017;07914.

2 British Medical Association. The state of pre and post-graduate medical recruitment in England, September 2017. London: BMA, 2017.

3 General Medical Council. Primary medical qualification factsheet. GMC, 2010. www.gmc-uk.org/Primary_Medical_ Qualification_2010.pdf [Accessed 03 February 2018].

4 Simpson JM, Esmail A, Kalra VS, Snow SJ. Writing migrants back into NHS history: addressing a 'collective amnesia' and its policy implications. J R Soc Med. 2010;103:392-396.

5 General Medical Council. List of registered medical practitioners statistics. GMC, 2017. www.gmc-uk.org/doctors/register/search_ stats.asp [Accessed 03 February 2018].

6 General Medical Council. Applying for registration with enforceable community rights. GMC. www.gmc-uk.org/doctors/registration_ applications/ec_rights.asp [Accessed 03 February 2018].

7 Paton A. A better deal for overseas doctors? Postgrad Med ] 1988;64:87-8.

8 Trewby P. International medical graduates: a tale of two scandals? Hosp Med 2005:66:380-1.

9 Trewby PN. Assisting international medical graduates applying for their first post in the UK: what should be done? Clin Med 2005;5:126-32.

10 Sandhu DP. Current dilemmas in overseas doctors' training. Postgrad Med J 2005;81:79-82.

11 Esmail A, Panagioti M, Kontopantelis E. The potential impact of Brexit and immigration policies on the GP workforce in England: a cross-sectional observational study of GP qualification region and the characteristics of the areas and population they served in September 2016. BMC Med 2017;15:191.

12 UK Visas and Immigration. Doctors and nurses to be taken out of Tier 2 visa cap. UK Visas and Immigration, 2018. www.gov. uk/government/news/doctors-and-nurses-to-be-taken-out-of-tier2-visa-cap [Accessed 03 July 2018].

13 Smith R. Profile of the GMC: Overseas doctors: diminishing controversy. BMJ 1989;298:1441-4.

14 Report of GMC inquiry. Br Med J 1975;2:183-8.

15 Editorial: Tests on overseas doctors. Br Med J 1975;4:542-3.

16 General Medical Council. The state of medical education and practice in the UK. GMC, 2011. www.gmc-uk.org/publications/10586.asp [Accessed 03 February 2018].

17 de Vries H, Sanderson P, Janta B et al. International comparison of ten medical regulatory systems: Egypt, Germany, Greece, India, Italy, Nigeria, Pakistan, Poland, South Africa and Spain. Santa Monica: RAND Corporation, 2009.

18 Ong YL, McFadden G, Gayen A. Induction for overseas qualified doctors. Hosp Med 2002;63:558-60.

19 Humphrey C, Hickman S, Gulliford MC. Place of medical qualification and outcomes of UK General Medical Council 'fitness to practise' process: cohort study. BMJ 2011;342:d1817.

20 Richards $T$. The overseas doctors training scheme: failing expectations. BMJ 1994:308:1627-31.

21 Slowther A, Lewando Hundt GA, Purkis J, Taylor R. Experiences of non-UK-qualified doctors working within the UK regulatory framework: a qualitative study. J R Soc Med 2012;105:157-65.

22 Kehoe A, McLachlan J, Metcalf J, Forrest S, Carter M, Illing J. Supporting international medical graduates' transition to their host-country: realist synthesis. Med Educ 2016;50:1015-32.
23 General Medical Council. Insurance indemnity and medico-legal support. GMC. www.gmc-uk.org/doctors/information_for_doctors/ insurance_and_indemnity.asp [Accessed 18 Feb 2018].

24 Porter E, Powell G. Recruitment of European Union general practitioners: developing a process for the analysis of English language training needs. Educ Prim Care 2005;16:5.

25 Janet I. The experiences of UK, EU and non-EU medical graduates making the transition to the UK workplace: ESRC Full Research Report. Swindon: ESRC, 2009.

26 Cross D, Smalldridge A. Improving written and verbal communication skills for international medical graduates: a linguistic and medical approach. Med Teach 2011;33:e364-7.

27 Rhodes P. Letters to a young doctor. Overseas doctors. Br Med J (Clin Res Ed) 1983;286:1047-9.

28 Mahajan J, Stark P. Barriers to education of overseas doctors in paediatrics: a qualitative study in South Yorkshire. Arch Dis Child 2007:92:219-23.

29 Welsh C. Training overseas doctors in the United Kingdom. They must be given accurate information about their job prospects. $B M]$ 2000;321:253-4.

30 Dosani S, Schroter S, MacDonald R, Connor J. Recruitment of doctors to non-standard grades in the NHS: analysis of job advertisements and survey of advertisers. BMJ 2003;327:961-4.

31 General Medical Council. Chapter one: Our data on doctors working in the UK. GMC. www.gmc-uk.org/Chapter_1_SOMEP_2015.pdf [Accessed 16 February 2018].

32 Simpson JM, Esmail A. The UK's dysfunctional relationship with medical migrants: the Daniel Ubani case and reform of out-ofhours services. Br J Gen Pract 2011;61:208-11.

33 Ballard K LP. An induction programme for European general practitioners coming to work in England: development and evaluation. Educ Prim Care 2004;15:11.

34 Linhao M, Forsyth DR, Zhaofen L. A Chinese doctor's experience of acute medicine in England. Clin Med 2010;10:480-3.

35 Hurst SA, Perrier A, Pegoraro R et al. Ethical difficulties in clinical practice: experiences of European doctors. J Med Ethics 2007;33:51-7.

36 Irish B, Patterson F. Selecting general practice specialty trainees: where next? Br J Gen Pract 2010;60:849-52.

37 Morrow G, Rothwell C, Burford B, Illing J. Cultural dimensions in the transition of overseas medical graduates to the UK workplace. Med Teach 2013;35:e1537-45.

38 Hashim A. Educational challenges faced by international medical graduates in the UK. Adv Med Educ Pract 2017;8:441-5.

39 Michalski K, Farhan N, Motschall E, Vach W, Boeker M. Dealing with foreign cultural paradigms: A systematic review on intercultural challenges of international medical graduates. PLoS One 2017;12:e0181330.

40 General Medical Council. Openness and honesty when things go wrong: the professional duty of candour. Manchester: GMC, 2015. www.gmc-uk.org/ethical-guidance/ethical-guidance-fordoctors/candour-openness-and-honesty-when-things-go-wrong/ the-professional-duty-of-candour [Accessed 14 August 2018].

41 Poyner A, Wood A, Herzberg J. A project to improve information technology skills for flexible trainees and overseas doctors. Health Info Libr J 2004:21:57-60.

42 Verma A, Griffin A, Dacre J, Elder A. Exploring cultural and linguistic influences on clinical communication skills: a qualitative study of International Medical Graduates. BMC Med Educ 2016;16:162.

43 General Medical Council. Revalidation. www.gmc-uk.org/doctors/ revalidation/faq_revalidation.asp [Accessed 03 February 2018].

44 Hoosen I, Callaghan R. A survey of workplace bullying of psychiatric trainees in the West Midlands. Psychiatr Bull 2004;28:3.

45 Carter M TN, Crampton P et al. Workplace bullying in the UK NHS: a questionnaire and interview study on prevalence, impact and barriers to reporting. BMJ Open 2013;3:e002628.

46 Esmail A, Everington S. Racial discrimination against doctors from ethnic minorities. BMJ 1993;306:691-2. 
47 Esmail A, Everington S. Asian doctors are still being discriminated against. BMJ 1997:314:1619.

48 Service NCA. About NCAS. www.ncas.nhs.uk/about-ncas [Accessed 15 February 2018].

49 Service NCA. National Clinical Assessment Service publications: The first eight years. www.ncas.nhs.uk/publications [Accessed 15 February 2018].

50 Rich AJ. An induction programme for first-appointment overseas doctors. Med Teach 1998;20:3.

51 Wawdhane S, Saraf V, Davidson S, Trewby P. Clinical attachments: fond farewell or new beginning? A survey of the attitudes and practice of medical consultants and international medical graduates. Postgrad Med J 2007;83:4.
52 General Medical Council. Welcome to UK practice. GMC, 2018. www.gmc-uk.org/doctors/WelcomeUK.asp [Accessed 15 February 2018].

53 Lineberry M, Osta A, Barnes M, Tas V, Atchon K, Schwartz A. Educational intervention for international medical graduates: a review and agenda. Med Educ 2015;49:17.

54 Hofstede G. Dimension of national cultures. www.geerthofstede.nl [Accessed 15 February 2018].

Address for correspondence: Dr Mustafa Jalal, Academic Department of Gastroenterology, Royal Hallamshire Hospital, Glossop Road, Sheffield S10 2JF, UK.

Email: mustafa.jalal@nhs.net

\section{The RCP Medical Training Initiative (MTI)}

Enabling trusts to recruit RCP-endorsed international medical graduates and foster links with hospitals around the world, while providing overseas trainees with the opportunity to work and train in the UK.

For more information, visit www.rcplondon.ac.uk/mti or email MTI@rcplondon.ac.uk
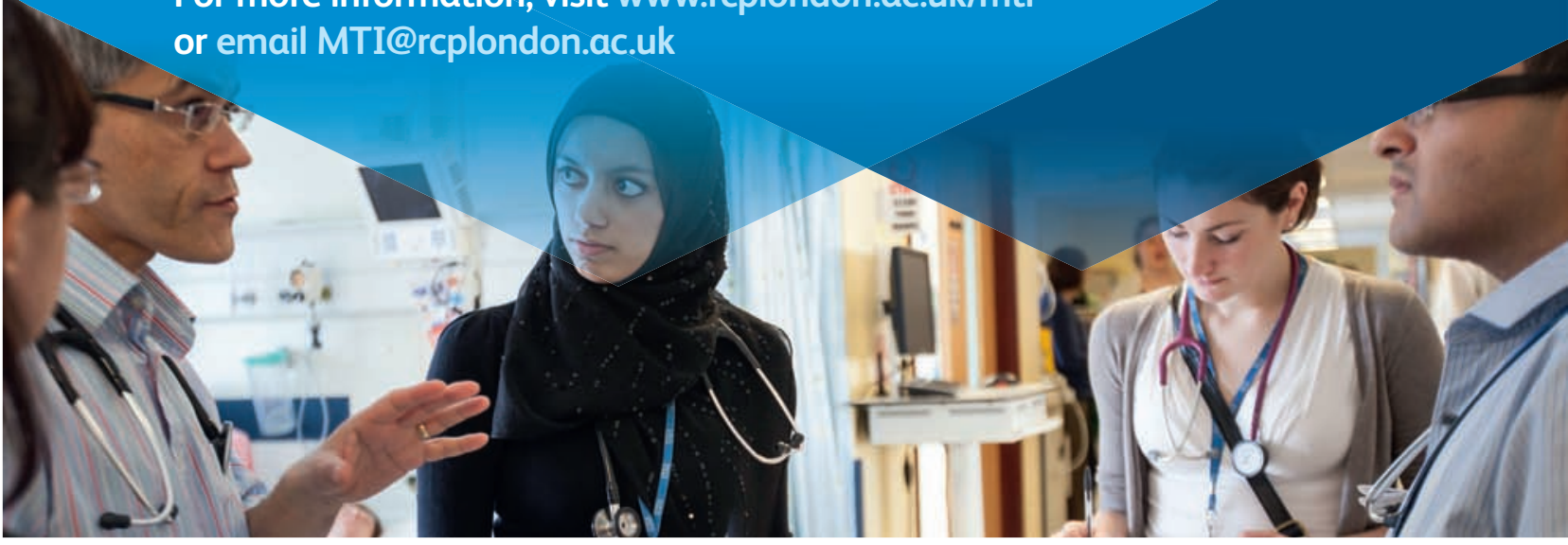